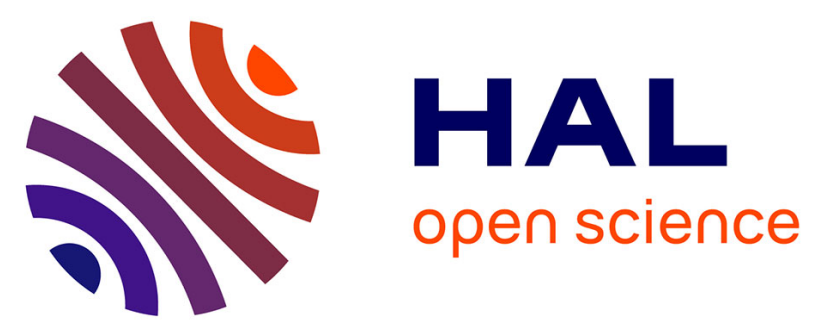

\title{
Hybrid-RRAM towards next generation of non-volatile memory: Coupling of oxygen vacancies and metal ions
}

Gilbert Sassine, Cecile Nail, Philippe Blaise, Benoit Sklenard, Mathieu Bernard, Rémy Gassilloud, Aurélie Marty, Marc Veillerot, Christophe Vallee, Etienne Nowak, et al.

\section{To cite this version:}

Gilbert Sassine, Cecile Nail, Philippe Blaise, Benoit Sklenard, Mathieu Bernard, et al.. HybridRRAM towards next generation of non-volatile memory: Coupling of oxygen vacancies and metal ions. Advanced Electronic Materials, 2018, 5 (2), pp.1800658. 10.1002/aelm.201800658 . cea-02885888

\section{HAL Id: cea-02885888 https://hal-cea.archives-ouvertes.fr/cea-02885888}

Submitted on 1 Jul 2020

HAL is a multi-disciplinary open access archive for the deposit and dissemination of scientific research documents, whether they are published or not. The documents may come from teaching and research institutions in France or abroad, or from public or private research centers.
L'archive ouverte pluridisciplinaire HAL, est destinée au dépôt et à la diffusion de documents scientifiques de niveau recherche, publiés ou non, émanant des établissements d'enseignement et de recherche français ou étrangers, des laboratoires publics ou privés. 


\section{WILEY-VCH}

DOI: 10.1002/ ((please add manuscript number))

\section{Article type: Full Paper}

Title Hybrid-RRAM Towards Next Generation of Non-volatile Memory: Coupling of Oxygen Vacancies and Metal Ions

Author(s), and Corresponding Author(s)* Gilbert Sassine*, Cécile Nail, Philippe Blaise, Benoit Sklenard, Mathieu Bernard, Rémy Gassilloud, Aurélie Marty, Marc Veillerot, Christophe Vallée, Etienne Nowak, and Gabriel Molas*

G. S., C. N., P. B., B. S., M. B., R. G., A. M., M. V., E.N., G.M.

CEA LETI Minatec Campus, 17 avenue des Martyrs, 38045 Grenoble, France

E-mail: gilbert.sassine@cea.fr, Gabriel.molas@cea.fr

C. V.

LTM CNRS, 17 avenue des Martyrs, 38045 Grenoble, France

Keywords: hybrid rram, reliability, atomistic simulations, nano-device

In this paper, the impact of copper and oxygen vacancy balance in filament composition as a key factor for oxide-based CBRAM (Hybrid RRAM) performances is investigated. To this aim, several RRAM technologies are studied using various resistive layers and top electrodes.

Material analyses allow to highlight the hybrid aspect of HRRAM conductive filament.

Density functional theory simulations are used to extract microscopic features and highlight differences from a material point of view. Integrated RRAM technology performances such as window margin, endurance and retention are then measured to analyze copper and oxygen vacancy influence on device characteristics. A new RRAM classification correlating filament composition and memory performances is proposed.

\section{Introduction}

Post-CMOS alternative technologies are becoming critical for chip industry. Recently, alternative emerging technologies have gained interest targeting new applications as embedded device market, new computer architecture paradigms or flash memory replacement. Resistive random access memories (RRAM) performances such as high scalability, ${ }^{[1]}$ fast 


\section{WILEY-VCH}

switching speed ${ }^{[2]}$ and good endurance ${ }^{[3]}$ make them potential candidates for standalone storage class or embedded memory. ${ }^{[4-6]}$ Today, even flash memory has not been able to combine all of these features, especially in terms of writing speed. Furthermore, scaling down to nanoscale size requires switching currents in the order of tens of $\mu \mathrm{A}$ with more critical minimal dimensions. For the former, studies have shown the ability of RRAM to operate at sub- $\mu \mathrm{A},{ }^{[7]}$ while novel integration solutions such as passive crossbars ${ }^{[8]}$ and $3 \mathrm{D}$ stacking have been proposed to overcome the latter and to achieve extremely high packing density. ${ }^{[9]}$ The understanding of switching mechanisms at device level is a key factor for a technology to be viable at very large scale integration. Different types of resistive memory devices have been studied in the past years such as oxide based memories (OxRAM) and conductive bridge memories (CBRAM). It should be noted that for both technologies it is very challenging to combine good cycling endurance, stable retention and high Window Margin (WM). Two distinct resistive states can be obtained based on a reversible filament formation (SET operation) and rupture (RESET operation) inside an insulating layer sandwiched between two electrodes; SET operation being the switching from a high resistive state (HRS) to a low resistive state (LRS) and RESET the reverse operation (HRS to LRS). In the case of CBRAM, metal ions coming from top electrode (TE) are introduced in the insulating layer. Working principle is based on a metallic filament formation and dissolution controlling performances. ${ }^{[10]}$ These devices present high WM, relatively low endurance and poor retention stability. ${ }^{[11,12]}$ In the case of OxRAM, oxygen vacancies creation and annihilation inside the oxide dominates the switching mechanism. ${ }^{[13-15]}$ This technology shows low WM combined to high endurance and stable retention. ${ }^{[3,16]}$ While lots of effort have been done lately to improve switching speed and power consumption in RRAM, ${ }^{[17,18]}$ several challenges need to be overcome, namely the high extrinsic (device to device) and intrinsic (cycle to cycle) variability in RRAM characteristics. ${ }^{[7]}$ High WM could potentially help solving this variability by maximizing the ratio of HRS over LRS. Moreover, coupling high WM and high 


\section{WILEY-VCH}

endurance (up to $10^{8}$ cycles required for storage class applications ${ }^{[19]}$ ) remains a critical issue. Combining CBRAM and OxRAM in one hybrid oxide-based CBRAM (HRRAM) where filament can be composed of metal ions and oxygen vacancies could offer alternative performances such as high WM coupled with high endurance. Recent studies have identified materials issues in oxide and metal based RRAM. ${ }^{[20,21]}$ However, material properties study is still lacking in HRRAM to guide stack choice (oxide vs electrodes) towards a given application. In a previous work, a trade-off between endurance, window margin and retention was demonstrated. When comparing various HRRAM electrical performances and filament composition, it appeared that material properties such as energy migration barrier of species composing switching filament is linked to HRRAM behavior. ${ }^{[22]}$ It has been shown that oxygen vacancies formation is needed to introduce top electrode metal ions in different oxides. ${ }^{[23-26]}$ Nevertheless, to our knowledge, the equilibrium between metal ions and oxygen vacancies dependence on the chosen material and its impact on device performances has never been investigated. Our study focuses on oxide/CuTeGe-based HRRAM, where $\mathrm{Cu}$-rich based conductive filament controls the switching mechanism inside an oxide insulating layer. ${ }^{[17,27,28]}$ In this work, the hybrid aspect of the conductive filament (composed of both $\mathrm{Cu}$ atoms and oxygen vacancies) is demonstrated based on Time of Flight Secondary Ion Mass Spectrometry profiles (ToF-SIMS). Afterward, filament composition is analyzed for various HRRAM technologies based on Density Functional Theory (DFT). To this aim, thermodynamic (based on defect formation enthalpy) and kinetics (based on defects migration energy) considerations are made. HRRAM devices are characterized to analyze typical performances such as WM, retention and endurance. Based on our simulations and experimental results, a comparison between different stacks exposes the impact of the balance between copper and oxygen vacancies on HRRAM performances, allowing us to propose a new HRRAM classification. 


\section{WILEY-VCH}

\section{Technological Details}

In this study, various RRAM technologies are investigated. The devices are integrated in 1T1R configuration using $130 \mathrm{~nm}$ CMOS transistor as selector. Memory stack is deposited following bottom electrode (BE)/switching material/top electrode (TE) structure. $5 \mathrm{~nm}$ of amorphous a- $\mathrm{HfO}_{2},{ }^{[26]} 3 \mathrm{~nm}$ of amorphous a- $\mathrm{Al}_{2} \mathrm{O}_{3},{ }^{[29]} 4 \mathrm{~nm}$ of $\mathrm{GdO}_{\mathrm{x}},{ }^{[30]}$ and $10 \mathrm{~nm}$ of $\mathrm{Ta}_{2} \mathrm{O}_{5}$ were deposited by PVD or ALD on different PVD BEs (titanium nitride-TiN and tungsten W). $20 \mathrm{~nm}$ of $\mathrm{CuTe}_{\mathrm{x}} \mathrm{Ge}_{\mathrm{y}}$ or $5 \mathrm{~nm}$ of Ti deposited by PVD was used as TE for HRRAM and OxRAM respectively. For the sake of comparison, a typical CBRAM $\left(\mathrm{Ag} / \mathrm{GeS}_{2}\right)^{[11]}$ is introduced in Figure 1. It has been demonstrated that Te and Ge are not involved in filament composition. ${ }^{[29]} \mathrm{Ge}$ is used to stabilize CuTe layer and to keep it amorphous during integration process, to prevent any segregation and phase separation. Typically, $10-20 \% \mathrm{Ge}$ is used $^{[31,32]}$ in CuTe alloys. Moreover, $\mathrm{CuTe}$ bound is polar and can easily be broken in $\mathrm{Cu}^{\delta+}$ and $\mathrm{Te}^{\gamma-}$ ions. Due to its high formation energy compared to $\mathrm{Cu}$, Te plays no role in the filament formation. Thus, only $\mathrm{Cu}$ ions are mobile under electric field. Consequently, in the following, $\mathrm{HfO}_{2} / \mathrm{Cu}, \mathrm{Al}_{2} \mathrm{O}_{3} / \mathrm{Cu}, \mathrm{Ta}_{2} \mathrm{O}_{5} / \mathrm{Cu}$ and $\mathrm{GdO}_{x} / \mathrm{Cu}$ will refer to $\mathrm{HfO}_{2} / \mathrm{CuTe}_{\mathrm{x}} \mathrm{Ge}_{\mathrm{y}}$, $\mathrm{Al}_{2} \mathrm{O}_{3} / \mathrm{CuTe}_{\mathrm{x}} \mathrm{Ge}_{\mathrm{y}}, \mathrm{Ta}_{2} \mathrm{O}_{5} / \mathrm{CuTe}_{\mathrm{x}} \mathrm{Ge}_{\mathrm{y}}$ and $\mathrm{GdO}_{\mathrm{x}} / \mathrm{CuTe}_{\mathrm{x}} \mathrm{Ge}_{\mathrm{y}}$ stacks respectively.

\section{Hybrid Filament in HRRAM}

\subsection{ToF-SIMS Measurements}

As indicated above, HRRAM is a device where both metallic ions and oxygen vacancies contribute to switching mechanism. Since a direct microscopic observation of an oxygen vacancy based filament at nanoscale level is still challenging, here we propose an indirect method based on Tof-SIMS measurements; a technique based on sputtering a surface with a focused ion beam and collecting ejected secondary ions. Spectra of copper and oxygen profiles versus sputtering time in HRS and LRS are presented in Figure 2.a and b for $\mathrm{Ta}_{2} \mathrm{O}_{5} / \mathrm{Cu}$ technology. In LRS state, $\mathrm{Cu}$ intensity in the $\mathrm{CuTe}_{2} \mathrm{Ge}$ region decreases (indicated 


\section{WILEY-VCH}

as less $\mathrm{Cu}$ in Figure 2.a). An increase of intensity is also observed in the signal incoming from the $\mathrm{Ta}_{2} \mathrm{O}_{5}$ region (indicated as more $\mathrm{Cu}$ in Figure 2.a). The copper content shift toward longer sputtering times corresponds to copper diffusion from the ion source layer (top electrode) toward the bottom electrode. This copper diffusion is consistent with a CBRAM behavior. On the other hand, when comparing LRS to HRS of oxygen profile in Figure 2.b, LRS state profile shows a decrease of oxygen content in the dielectric. Moreover, an increase of oxygen content is also observed in the $\mathrm{CuTe}_{2} \mathrm{Ge}$ region. This oxygen content shift corresponds to an oxygen diffusion toward the surface, leading to oxygen vacancies formation in the oxide as represented in Figure 2.c. This oxygen diffusion is consistent with OxRAM behavior. It is worth highlighting that as the ionization yield depends of the atomic environment of the element, when studying a stack of several layers, some matrix effects can appear at the interfaces. Moreover, during the sputtering some atoms can be repelled in the sub layers, thus in the spectra represented in Figure 2.a and b the interfaces positions are roughly estimated. As observed, both copper and oxygen profiles evolve when an external bias is applied. This behavior is associated to a hybrid behavior between pure CBRAM, where the filament is mainly composed of diffused metal and pure OxRAM where the filament is made of a path of local oxygen deficiencies namely vacancies. This hybrid mechanism is strongly correlated between vacancies and copper. Oxygen vacancies formed in the oxide weaken the chemical barrier properties, which eases copper diffusion. Stated differently, copper can easily follow paths formed by the organization of vacancies in the dielectric, in particular vacancies can be filled by copper atoms.

\subsection{Atomistic Simulations}

In order to give insight on microscopic mechanisms that could occur in all our integrated devices $\left(\mathrm{HfO}_{2} / \mathrm{Cu}, \mathrm{Ta}_{2} \mathrm{O}_{5} / \mathrm{Cu}, \mathrm{Al}_{2} \mathrm{O}_{3} / \mathrm{Cu}\right.$ and $\left.\mathrm{GdO}_{x} / \mathrm{Cu}\right)$, atomistic simulations were performed. Combining defect formation enthalpy $(\Delta H)$ and migration energy barrier $\left(E_{a}\right)$, the most favorable defects that could compose a filament can be extracted. $\Delta H$ is the total energy 


\section{WILEY-VCH}

difference between an initial and a final state (introducing a new defect) representing an event between the oxide and the TE. $E_{a}$ is the energy needed for a defect to diffuse in the oxide. The lower these values are, the more favorable the associated event is.

Table 1 summarizes the results. It can be noted, as seen in our calculations, that oxygen vacancy's formation is required to form the filament. $\Delta H$ of copper interstitial next to Oxygen vacancy site $\left(\mathrm{Cu}_{\mathrm{i}} \mathrm{V}_{\mathrm{O}}\right)$ represents the lowest values in all cases validating the hybrid aspect of the formed filament. On the other hand, $\Delta H$ and $E_{a}$ of $\mathrm{V}_{\mathrm{O}}$ in $\mathrm{HfO}_{2}$ and $\mathrm{Ta}_{2} \mathrm{O}_{5}$ are lower than in $\mathrm{Al}_{2} \mathrm{O}_{3}$ and $\mathrm{GdO}_{x}$. Consequently, two filament features representing two different types of HRRAM could be identified: HRRAM where only $\mathrm{Cu}_{i} \mathrm{~V}_{0}$ defect is moving during memory operation, and HRRAM where both $\mathrm{Cu}_{\mathrm{i}} \mathrm{V}_{\mathrm{O}}$ and $\mathrm{V}_{\mathrm{O}}$ are moving. In $\mathrm{HfO}_{2}, \mathrm{Cu}_{\mathrm{i}} \mathrm{V}_{\mathrm{O}}$ introduction in the oxide are more favorable ( $\Delta H$ and $E_{a}$ lower) than copper interstitial $\left(\mathrm{Cu}_{\mathrm{i}}\right)$. Thus, filament in $\mathrm{HfO}_{2}$ could mainly be composed of $\mathrm{V}_{\mathrm{O}}$ and $\mathrm{Cu}_{\mathrm{i}} \mathrm{V}_{\mathrm{O}}$. In the case of $\mathrm{Ta}_{2} \mathrm{O}_{5}, \mathrm{Cu}_{\mathrm{i}}$ has a lower $\Delta H$ than $\mathrm{V}_{\mathrm{O}}$, nevertheless, it is easier to introduce and remove $\mathrm{Cu}_{\mathrm{i}}$ when it is associated to $\mathrm{V}_{\mathrm{O}}\left(\Delta H \mathrm{Cu}_{\mathrm{i}} \mathrm{V}_{\mathrm{O}}=0.5 \mathrm{eV}\right)$. While $\Delta H$ of $\mathrm{V}_{\mathrm{O}}$ is relatively high, it is combined to low migration energy, making it favorable to diffuse. Thus, in $\mathrm{Ta}_{2} \mathrm{O}_{5}$ the switching mechanism involves all of these studied defects. On the other hand, in $\mathrm{Al}_{2} \mathrm{O}_{3}$ and $\mathrm{GdO}_{x}, \mathrm{Cu}_{\mathrm{i}} \mathrm{V}_{\mathrm{O}}$ introduction in the oxide is the most favorable defect $\left(\Delta H\right.$ in the order of $0.6 \mathrm{eV}$ vs $3.8 \mathrm{eV}$ for $\mathrm{V}_{\mathrm{O}}$ in $\mathrm{Al}_{2} \mathrm{O}_{3}$ and $1.2 \mathrm{eV}$ vs $4.1 \mathrm{eV}$ for $\mathrm{V}_{\mathrm{O}}$ in $\left.\mathrm{GdO}_{\mathrm{x}}\right)$. Moreover, by introducing aluminum atoms in $\mathrm{GdO}_{\mathrm{x}}$ structure, $\Delta H \mathrm{Cu}_{\mathrm{i}} \mathrm{V}_{\mathrm{O}}$ is further reduced leading to a similar behavior as in $\mathrm{Al}_{2} \mathrm{O}_{3}$. Although $\mathrm{V}_{\mathrm{O}}$ are necessary in HRRAM filament composition, they are either as favorable as $\mathrm{Cu}_{\mathrm{i}} \mathrm{V}_{\mathrm{O}}$ defect (as in $\mathrm{HfO}_{2}$ ) or less favorable (as in $\mathrm{Al}_{2} \mathrm{O}_{3}$ and $\mathrm{GdO}_{\mathrm{x}}$ ). In the case of $\mathrm{Al}_{2} \mathrm{O}_{3}$ and $\mathrm{GdO}_{\mathrm{x}}$, once $\mathrm{V}_{\mathrm{O}}$ are created to introduce $\mathrm{Cu}$ ions during filament formation, $\mathrm{Cu}_{\mathrm{i}} \mathrm{V}_{\mathrm{O}}$ are more favorable to be the core of switching mechanism at the expense of $\mathrm{V}_{0}$. However, in $\mathrm{HfO}_{2}$ and $\mathrm{Ta}_{2} \mathrm{O}_{5}$ both $\mathrm{Cu}_{\mathrm{i}} \mathrm{V}_{\mathrm{O}}$ and $\mathrm{V}_{\mathrm{O}}$ defects can participate to filament formation and disruption. Indeed in $\mathrm{Ta}_{2} \mathrm{O}_{5}$, $\Delta H \mathrm{~V}_{\mathrm{O}}$ is higher than $\Delta H \mathrm{Cu}_{\mathrm{i}}$, but is coupled to a very low migration energy making its diffusion favorable. Figure 3.a and $\mathbf{b}$ show the diffusion barrier of $\mathrm{Cu}_{\mathrm{i}}, \mathrm{V}_{\mathrm{O}}$, and $\left(\mathrm{Cu}_{\mathrm{i}} \mathrm{V}_{\mathrm{O}}\right)$ 


\section{WILEY-VCH}

between two sites in $\mathrm{Al}_{2} \mathrm{O}_{3}$ and $\mathrm{HfO}_{2}$ respectively; $\mathrm{Al}_{2} \mathrm{O}_{3} / \mathrm{Cu}$ and $\mathrm{HfO}_{2} / \mathrm{Cu}$ being two devices with different filament features. As we can clearly see, in the case of $\mathrm{Al}_{2} \mathrm{O}_{3} / \mathrm{Cu},\left(\mathrm{Cu}_{i} \mathrm{~V}_{\mathrm{O}}\right)$ is the most favorable to be introduced and removed in the filament. On the other hand, in the case of $\mathrm{HfO}_{2}$, both $\mathrm{Vo}_{\mathrm{O}}$ and $\left(\mathrm{Cu}_{\mathrm{i}} \mathrm{V}_{\mathrm{O}}\right)$ are favorable compared to $\mathrm{Cu}_{\mathrm{i}}$.

\section{HRRAM Classification versus Performances}

It has been shown that during cycling, non-reversible defect generation gradually degrades the oxide leading to device failure when the maximum number of cycles is reached. ${ }^{[26,33,34]}$ Consequently, limiting non-reversible defect generation is a key to improve endurance. Based on our simulation results, different types of filament are identified. Although $\mathrm{V}_{\mathrm{O}}$ are required to favor $\mathrm{Cu}$ insertion leading to a hybrid filament, $\mathrm{V}_{\mathrm{O}}$ can become hard to remove and be source of defect generation eventually leading to oxide degradation as in $\mathrm{GdO}_{\mathrm{x}} / \mathrm{Cu}$. In a material where $\mathrm{Cu}_{\mathrm{i}} \mathrm{V}_{\mathrm{O}}$ are more favorable than $\mathrm{V}_{\mathrm{O}}$, switching filament is richer in $\mathrm{Cu}$. However, the energy required to remove the small amount of $V_{O}$ is higher than for removing $\mathrm{Cu}_{\mathrm{i}} \mathrm{V}_{\mathrm{O}}$. To remove $\mathrm{V}$, higher energy should be provided to the oxide, leading to higher defect generation. Moreover, favoring further $\mathrm{Cu}_{\mathrm{i}} \mathrm{V}_{\mathrm{O}}$ at the expense of $\mathrm{V}_{\mathrm{O}}$ as in $\mathrm{GdO}_{\mathrm{x}}-\mathrm{Al} / \mathrm{Cu}$ and $\mathrm{Al}_{2} \mathrm{O}_{3} / \mathrm{Cu}$ leads to a hybrid filament with less $\mathrm{V}_{\mathrm{O}}$ in its vicinity. In this case, the generation of non-reversible defects decreases leading to higher endurance. As completely removing $\mathrm{V}_{\mathrm{O}}$ from filament formation cannot be considered to decrease defect generation, Vo need to be easily removed to improve endurance. This can be obtained by adjusting $\mathrm{Cu}_{\mathrm{i}} \mathrm{V}_{\mathrm{O}} / \mathrm{V}_{\mathrm{O}}$ balance. In particular, when $\mathrm{V}_{\mathrm{O}}$ and $\mathrm{Cu}_{\mathrm{i}} \mathrm{V}_{\mathrm{O}}$ have the same occurrence probability in SET and RESET operations, they both participate to filament formation and disruption. $\mathrm{V}_{\mathrm{O}}$ and $\mathrm{Cu}_{\mathrm{i}} \mathrm{V}_{\mathrm{O}}$ are thus easily recovered during RESET, leading to low defect generation and good endurance. It can be noted that if migration energy barrier of both species is high, endurance will be degraded due to the high required energy to switch the memory. ${ }^{[33]}$ 


\section{WILEY-VCH}

Based on these results, Two groups of HRRAM can be identified as presented in Figure 4: 1) $\mathrm{Cu}_{\mathrm{i}} \mathrm{V}_{\mathrm{O}}$ is favored at the expense of $\mathrm{V}_{\mathrm{O}}$ leading to difficult $\mathrm{V}_{\mathrm{O}}$ recovery and earlier oxide degradation (lower endurance). 2) $\mathrm{Vo}_{\mathrm{O}}$ as favorable as $\mathrm{Cu}_{\mathrm{i}} \mathrm{V}_{\mathrm{O}}$ to be removed leads to a $\mathrm{V}_{\mathrm{o}}$ easy to recover and thus low defect generation (high endurance). It can be noted that in the case of Vo becoming more favorable than $\mathrm{Cu}_{\mathrm{i}} \mathrm{V}_{\mathrm{O}}$, the filament is no longer considered as hybrid and is mainly composed of $\mathrm{V}_{\mathrm{O}}$, leading to OxRAM behavior.

The impact of filament composition on device performances is shown in Figure 5. In order to compare device performances, three different features could be evaluated: window margin being the ratio between HRS and LRS, endurance being the maximum of SET/RESET cycles a cell can reach before final failure (oxide breakdown) and retention representing the temperature stability over time. These characteristics are interdependent; improving two features leads to the degradation of the third one. In particular, increasing WM and endurance degrades retention. Here, we compare the best endurance that could be reached for various integrated technologies and we correlate the results with filament composition. Figure 5.a illustrates WM evolution with cycling endurance. Experimental results comply with HRRAM classification based on atomistic simulations (Figure 4). Red and blue colors represent devices with TiN and $\mathrm{W}$ as bottom electrode respectively. Endurance is lower in $\mathrm{Al}_{2} \mathrm{O}_{3} / \mathrm{Cu}$ and $\mathrm{GdO}_{\mathrm{x}} / \mathrm{Cu}$ than in $\mathrm{HfO}_{2} / \mathrm{Cu}$ (details in supplementary material). Adjusting $\mathrm{V}_{\mathrm{O}}$ and $\mathrm{Cu}_{\mathrm{i}} \mathrm{V}_{\mathrm{O}}$ competition in the filament leads to different performances. If $\mathrm{V}_{\mathrm{O}}$ is as favorable as $\mathrm{Cu}_{\mathrm{i}} \mathrm{V}_{\mathrm{O}}$ to be introduced and diffused during SET and RESET $\left(\mathrm{HfO}_{2} / \mathrm{Cu}\right)$, endurance is improved. If $\mathrm{V}_{\mathrm{O}}$ is less favorable $\left(\mathrm{Al}_{2} \mathrm{O}_{3} / \mathrm{Cu}\right.$ and $\left.\mathrm{GdO}_{\mathrm{x}} / \mathrm{Cu}\right)$, endurance is degraded. In the latter, Vo presence, needed to introduce $\mathrm{Cu}$ in the oxide, are less favorable compared to $\mathrm{Cu}_{\mathrm{i}} \mathrm{V}_{\mathrm{O}}$. These samples present an early oxide degradation (lower endurance). Comparing $\mathrm{Al}_{2} \mathrm{O}_{3}$ and $\mathrm{GdO}_{\mathrm{x}}$ where $\mathrm{Cu}_{\mathrm{i}} \mathrm{V}_{\mathrm{O}}$ dominates the switching mechanism, $\mathrm{GdO}_{\mathrm{x}}$ has a lower endurance than $\mathrm{Al}_{2} \mathrm{O}_{3}$. This can be due to a lower defect enthalpy and energy migration barrier (0.6 vs $1.2 \mathrm{eV}$ for $\Delta H$ and 1.4 vs $3.44 \mathrm{eV}$ for $E_{a}$ ). As previously seen, by introducing $\mathrm{Al}$ in $\mathrm{GdO}_{\mathrm{x}}$ structure, $\mathrm{Cu}_{\mathrm{i}} \mathrm{V}_{\mathrm{O}} \Delta H$ is 


\section{WILEY-VCH}

further reduced leading to a comparable filament composition as in $\mathrm{Al}_{2} \mathrm{O}_{3}$. This is confirmed in Figure 5.a: by doping $\mathrm{GdO}_{\mathrm{x}}$ with aluminum, endurance is improved and tends toward $\mathrm{Al}_{2} \mathrm{O}_{3}$. Combining endurance results and atomistic calculations, it appears that $\mathrm{Al}$ presence in the oxide favors $\mathrm{Cu}$ insertion next to Vo. An OxRAM and a CBRAM are introduced in Figure 5 for comparison sakes.

Consequently, in a material where $\mathrm{Cu}_{\mathrm{i}} \mathrm{V}_{\mathrm{O}}$ is more favorable than $\mathrm{V}_{\mathrm{O}}$, favoring further $\mathrm{Cu}_{\mathrm{i}} \mathrm{V}_{\mathrm{O}}$ increases the endurance. In other words, improving $\mathrm{Cu}$ insertion leads to a filament easier to form and disrupt during SET and RESET, leading to a better endurance regardless WM.

Figure 5.b and c represent the comparison between best case and worst case for endurance and data retention respectively. In figure 5.b, endurance of $\mathrm{HfO}_{2} / \mathrm{Cu}\left(6.10^{9}\right.$ cycles $)$ is compared to $\mathrm{GdO}_{x}$ (where only $10^{3}$ cycles can be reached). On the other hand, in Figure 5.c, temperature stability of the same devices in Figure $5 . \mathrm{b}$ is compared at $200^{\circ} \mathrm{C}$. As clearly seen, the higher the endurance is, the lower the retention is. One should note that endurance performances are not only related to the hybrid character of the RRAM, but are also linked to the respective $\mathrm{V}_{\mathrm{O}}, \mathrm{Cu}$ and $\mathrm{Cu}_{\mathrm{i}} \mathrm{V}_{\mathrm{O}}$ energy costs. Moreover, the highest endurance/WM tradeoff is due to the use of a tungsten based bottom electrode which favors the RESET due to tungsten high thermal conductivity favoring thermal dissipation. Thus, the energy needed to RESET the device is lowered. These conditions favor the cycling capacities of the device at the expense of the temperature stability as shown in figure S2.b.

To further investigate the difference between the two filament features presented above, we have studied forming operation with two different polarizations in $\mathrm{HfO}_{2} / \mathrm{Cu}$ and $\mathrm{Al}_{2} \mathrm{O}_{3} / \mathrm{Cu}$ (more details in supplementary materials). Figure S.5 represents the time to breakdown tBD versus forming voltage $\left(\mathrm{V}_{\mathrm{f}}\right)$. For $\mathrm{HfO}_{2} / \mathrm{Cu}, \mathrm{t}_{\mathrm{BD}}$ and $\mathrm{V}_{\mathrm{f}}$ are similar in both polarizations. In the case of $\mathrm{Al}_{2} \mathrm{O}_{3} / \mathrm{Cu}$, higher forming voltage is observed for short tBD when TE is negatively polarized preventing $\mathrm{Cu}$ insertion in the oxide. $\mathrm{HfO}_{2} / \mathrm{Cu}$ shows similar switching mechanism in both polarizations while $\mathrm{Al}_{2} \mathrm{O}_{3} / \mathrm{Cu}$ exposes different working principle depending on 


\section{WILEY-VCH}

polarization. In $\mathrm{HfO}_{2}$, The conductive filament formation with $\mathrm{Cu}_{i} \mathrm{~V}_{\mathrm{O}}$ or only $\mathrm{V}_{\mathrm{O}}$ has no impact on $t_{B D}$. In $\mathrm{Al}_{2} \mathrm{O}_{3}$, as the introduction of copper is more favorable than oxygen vacancies, its introduction in direct forming eases filament formation and lower forming voltage.

Consequently, we present a panel of filament composition to be aimed depending on the targeted application. CBRAMs present high WM while OxRAMs show high endurance and stable retention. Combining OxRAM and CBRAM in one hybrid HRRAM, performance compromises could be achieved. Large WM and high endurance are obtained in $\mathrm{HfO}_{2} / \mathrm{Cu}$ owing to $\mathrm{Vo} / \mathrm{Cu}_{\mathrm{i}} \mathrm{V}_{\mathrm{o}}$ equilibrium in the switching filament. On the other hand, large $\mathrm{WM}$ and stable retention could be achieved due to favoring $\mathrm{Cu}_{\mathrm{i}} \mathrm{V}_{\mathrm{O}}$ at the expense of $\mathrm{V}_{\mathrm{O}}$ as in $\mathrm{GdO}_{\mathrm{x}} / \mathrm{Cu}$ and $\mathrm{Al}_{2} \mathrm{O}_{3} / \mathrm{Cu}$.

\section{Conclusion}

In this work, the impact of balancing metal ions and oxygen vacancies in HRRAM filament on device performances was investigated. Filament composition was studied by first principle calculations and maximum endurance was identified for different HRRAM. Combining experimental results and atomistic simulations, we highlighted filament features to improve endurance characteristics. In particular, we demonstrated that in HRRAM, Vo are necessary to form a $\mathrm{Cu}$-rich filament. The switching mechanism is thus controlled by $\mathrm{Cu}$ ions and Oxygen vacancies. However, two types of filament were put in evidence. Filament where $\mathrm{Cu}_{\mathrm{i}} \mathrm{V}_{\mathrm{O}}$ are more favorable to control switching mechanism at the expense of $\mathrm{Vo}_{\mathrm{O}}\left(\mathrm{Al}_{2} \mathrm{O}_{3}\right.$ and $\left.\mathrm{GdO}_{\mathrm{x}}\right)$ presents Vo hard to be recovered leading to early oxide degradation (low endurance). Decreasing $\mathrm{Cu}_{\mathrm{i}} \mathrm{V}_{\mathrm{O}}$ formation enthalpy and diffusion barrier in oxide leads to filament richer in $\mathrm{Cu}_{\mathrm{i}} \mathrm{V}_{\mathrm{O}}$ (poorer in $\mathrm{V}_{\mathrm{O}}$ ) and improves endurance. However, $\mathrm{V}_{\mathrm{O}}$ need to be easily removed during RESET to further improve endurance. This can be obtained by adjusting $\mathrm{Cu}_{\mathrm{i}} \mathrm{V}_{\mathrm{O}} / \mathrm{V}_{\mathrm{O}}$ balance ( $\mathrm{V}_{\mathrm{O}}$ as favorable as $\mathrm{Cu}_{\mathrm{i}} \mathrm{V}_{\mathrm{O}}$ to be introduced and removed from oxide). In this case, 


\section{WILEY-VCH}

both defects participate in filament formation and disruption. $\mathrm{V}_{\mathrm{O}}$ and $\mathrm{Cu}_{i} \mathrm{~V}_{\mathrm{O}}$ are thus easily recovered leading to low defect generation (higher endurance as in $\mathrm{HfO}_{2} / \mathrm{Cu}$ ). In summary, we presented a panel of filament composition, giving insights to choose the most suitable technology (RRAM resistive layer and electrodes) for a given application with required specifications.

\section{Acknowledgements}

This work has been partially supported by the European 621217 PANACHE project. "Gilbert Sassine and Cécile Nail contributed equally to this work." This work was supported by the H2020 WakeMeUp project.

Received: ((will be filled in by the editorial staff))

Revised: ((will be filled in by the editorial staff)) Published online: ((will be filled in by the editorial staff))

\section{References}

B. Govoreanu, G. S. Kar, Y-Y. Chen, V. Paraschiv, S. Kubicek, A. Fantini, I. P. Radu,

L. Goux, S. Clima, R. Degraeve, N. Jossart, O. Richard, T. Vandeweyer, K. Seo, P.

Hendrickx, G. Pourtois, H. Bender, L. Altimime, D. J. Wouters, J. A. Kittl, M. Jurczak, 2011

International Electron Devices Meeting, Washington DC, 2011, 31.6.1.

[2] A. C. Torrezan, J. P. Strachan, G. Medeiros-Ribeiro, R. S. Williams, Nanotechnology

2011, 22, 485203.

[3] M-J. Lee, C. B. Lee, D. Lee, S. R. Lee, M. Chang, J. H. Hur, Y-B. Kim, C-J. Kim, D.

H. Seo, S. Seo, U-I. Chung, I-K. Yoo, K. Kim, Nature Materials 2011, 10, 625.

[4] S. Sills, S. Yasuda, J. Strand, A. Calderoni, K. Aratani, A. Johnson, N. Ramaswamy, 2014 Symposium on VLSI Technology (VLSI-Technology): Digest of Technical Papers, Honolulu, 2014, 1.

[5] J.R. Jameson, P. Blanchard, C. Cheng, J. Dinh, A. Gallo, V. Gopalakrishnan, C.

Gopalan, B. Guichet, S. Hsu, D. Kamalanathan, D. Kim, F. Koushan, M. Kwan, K. Law, D.

Lewis, Y. Ma, V. McCaffrey, S. Park, S. Puthenthermadam, E. Runnion, J. Sanchez, J. Shields, K. Tsai, A. Tysdal, D. Wang, R. Williams, M.N. Kozicki, J. Wang, V. Gopinath, S. Hollmer, 


\section{WILEY-VCH}

M. Van Buskirk, 2013 IEEE International Electron Devices Meeting, Washington DC, 2013, 30.1.1.

[6] Z. Wei, K. Eriguchi, S. Muraoka, K. Katayama, R. Yasuhara, K. Kawai, Y. Ikeda, M. Yoshimura, Y. Hayakawa, K. Shimakawa, T. Mikawa, S. Yoneda, 2015 IEEE International Electron Devices Meeting (IEDM), Washington DC, 2015, 7.7.1.

[7] A. Fantini, L. Goux , R. Degraeve , D.J. Wouters, N. Raghavan , G. Kar , A. Belmonte, Y.-Y. Chen, B. Govoreanu , M. Jurczak, 2013 5th IEEE International Memory Workshop, Monterey CA, 2013, 30.

[8] M. Prezioso, F. Merrikh-Bayat, B. D. Hoskins, G. C. Adam, K. K. Likharev, D. B. Strukov, Nature 2011, 521, 61.

[9] Y. Bai, H. Wu, K. Wang, R. Wu, L. Song, T. Li, J. Wang, Z. Yu, H. Qian, Scientific Reports 2015, 5, 13785.

[10] I. Valov, R. Waser, J. R. Jameson, M. N Kozicki, Nanotechnology 2011, 22, 289502.

[11] E. Vianello, C. Cagli, G. Molas, E. Souchier, P. Blaise, C. Carabasse, G. Rodriguez, V. Jousseaume, B. De Salvo, F. Longnos, F. Dahmani, P. Verrier, D. Bretegnier, J. Liebault, 2012 Proceedings of the European Solid-State Device Research Conference (ESSDERC), Bordeaux, 2012, 278.

[12] S. Pi, M. G. Sadrabadi, J. C. Bardin, Q. Xia, Nature Communication 2015, 6, 7519.

[13] D. B. Strukov, G. S. Snider, D. R. Stewart, R. S. Williams, Nature, 2009, 459, 1154.

[14] J. J. Yang, D. B. Strukov, D. R. Stewart, Nature Nanotechnology, 2013, 8, 13.

[15] G. Sassine, S. La barbera, N. Najjari, M. Minvielle, C. Dubourdieu, F. Alibart, Journal of Vacuum Science \& Technology B, Nanotechnology and Microelectronics: Materials, Processing, Measurement, and Phenomena, 2016, 34, 012202-1.

[16] T-C. Chang, K-C. Chang, T-M. Tsai, T-J. Chu, S. M. Sze, Materials Today, 2016, 19, 254.

[17] S. Menzel, U. Böttger, M. Wimmer, M. Salinga, Adv. Funct. Mater. 2015, 25, 6306. 


\section{WILEY-VCH}

[18] G. Sassine, C. Cagli, J. Nodin, G. Molas and E. Nowak, IEEE Journal of the Electron Devices Society, 2018, 6, 696.

[19] ITRS, “Executive Report,” http://www.itrs2.net/, accessed: 2015.

[20] L. Zhu, J. Zhou, Z. Guo, Z. Sun, J Materiomics, 2015, 1, 285.

[21] J. Shang, G. Liu, H. Yang, X. Zhu, X. Chen, H. Tan, B. Hu, L. Pan, W. Xue, R-W. Li, Adv. Funct. Mater. 2014, 24, 2171.

[22] C. Nail, G. Molas, P. Blaise, B. Sklenard, R. Berthier, M. Bernard, L. Perniola, G. Ghibaudo, C. Vallée, IEEE Transactions on Electron Devices, 2017, 64, 4479.

[23] R. Waser, R. Dittmann, G. Staikov, Kristof Szot, Adv. Mater. 2009, 21, 2632.

[24] M. Saadi, P. Gonon, C. Vallée, C. Mannequin, H. Grampeix, E. Jalaguier, F. Jomni, A. Bsiesy, Journal of Applied Physics 2016, 119, 114501.

[25] G. Molas, E. Vianello, F. Dahmani, M. Barci, P. Blaise, J. Guy, A. Toffoli, M. Bernard, A. Roule, F. Pierre, C. Licitra, B. De Salvo, L. Perniola, 2014 IEEE International Electron Devices Meeting, San Francisco CA, 2014, 6.1.1.

[26] C. Nail, G. Molas, P. Blaise, G. Piccolboni, B. Sklenard, C. Cagli, M. Bernard, A. Roule, M. Azzaz, E. Vianello, C. Carabasse, R. Berthier, D. Cooper, C. Pelissier, T. Magis, G. Ghibaudo, C. Vallée, D. Bedeau, O. Mosendz, B. De Salvo, L. Perniola, 2016 IEEE International Electron Devices Meeting (IEDM), San Francisco CA, 2016, 4.5.1.

[27] U. Celano, L. Goux, A. Belmonte, K. Opsomer, A. Franquet, A. Schulze, C. Detavernier, O. Richard, H. Bender, M. Jurczak, W. Vandervorst, Nano Lett. 2014, 14, 2401.

[28] D. S. Jeong, R. Thomas, R. S. Katiyar, J. F. Scott, H. Kohlstedt, A. Petraru, C. S. Hwang, Rep. Prog. Phys. 2012, 75, 076502.

[29] C. Nail, P. Blaise, G. Molas, M. Bernard, A. Roule, A. Toffoli, L. Perniola, C. Vallée, Journal of Applied Physics, 2017, 122, 024503. 


\section{WILEY-VCH}

[30] M. Barci, J. Guy, G.Molas, E. Vianello, A. Toffoli, J. Cluzel, A. Roule, M. Bernard, C.

Sabbione, L. Perniola, B. De Salvo, 2014 IEEE International Reliability Physics Symposium, Waikoloa HI, 2014, 5E.3.1.

[31] W. Devulder, K. Opsomer, M. Jurczak, L. Goux and C. Detavernier, 2015 IEEE International Interconnect Technology Conference and 2015 IEEE Materials for Advanced Metallization Conference (IITC/MAM), Grenoble, 2015, 215.

[32] K. Ohba, S. Yasuda, T. Mizuguchi, K. Aratani, M. Shimuta, A. Kouchiyama, M.Ogasawara (Sony Semiconductor Solutions Corp), US 13018744, 2011.

[33] S. Balatti, S. Ambrogio, Z.-Q. Wang, S. Sills, A. Calderoni, N. Ramaswamy, D. Ielmini, 2014 IEEE International Electron Devices Meeting, San Francisco CA, 2014, 14.3.1.

[34] G. Sassine, D. Alfaro Robayo, C. Nail, J.-F. Nodin, J. Coignus, G. Molas, E. Nowak, 2018 IEEE International Memory Workshop (IMW), Kyoto, 2018, 1.

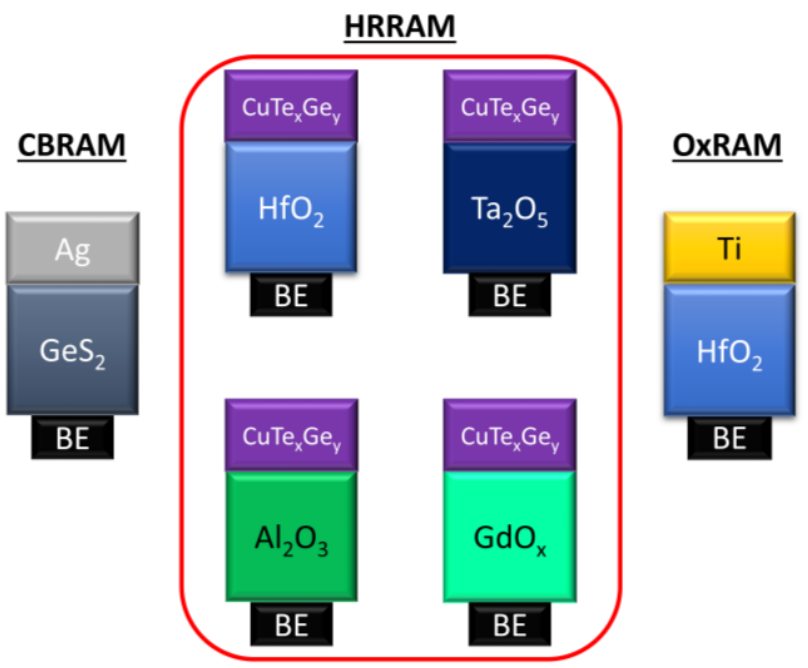

Figure 1. Schematics of RRAM stacks studied in this work. In HRRAM, switching mechanism is controlled by hybrid filaments composed of both $\mathrm{Cu}$ and $\mathrm{V}_{O}$ species. 
WILEY-VCH
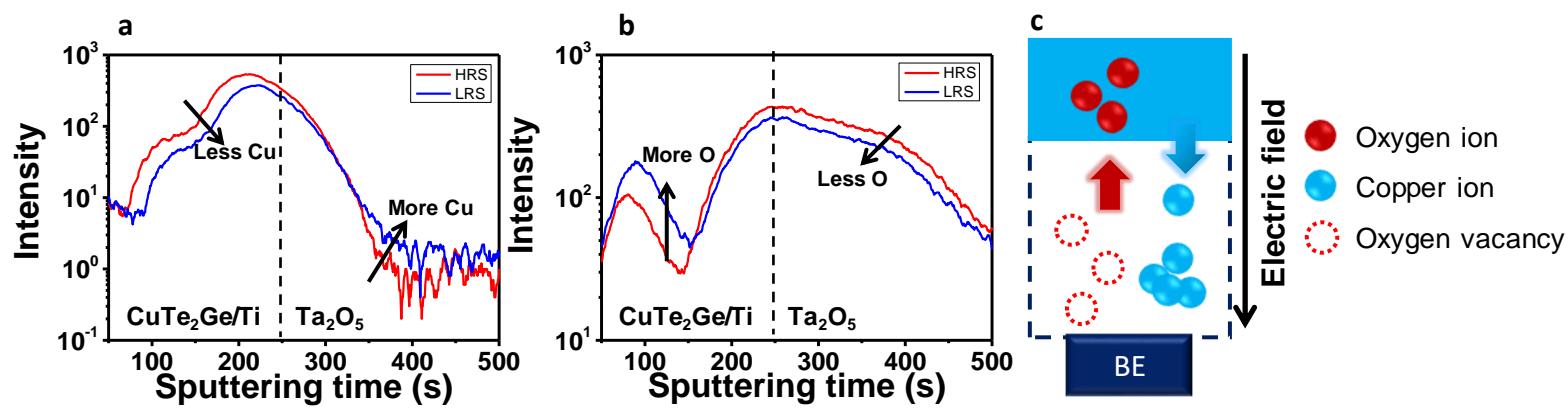

Figure 2. ToF-SIMS profiles. (a) and (b) copper and oxygen ToF-SIMS profiles in HRS (red lines) and LRS (blue lines) for $\mathrm{Ta}_{2} \mathrm{O}_{5} / \mathrm{Cu}$ memory. In LRS state, $\mathrm{Cu}$ intensity in the $\mathrm{CuTe}_{2} \mathrm{Ge} / \mathrm{Ti}$ region decreases, and increases in $\mathrm{Ta}_{2} \mathrm{O}_{5}$ region. Inversely, Oxygen decreases in $\mathrm{Ta}_{2} \mathrm{O}_{5}$ and increases in $\mathrm{CuTe}_{2} \mathrm{Ge} / \mathrm{Ti}$ leading to $\mathrm{V}_{\mathrm{O}}$ formation in $\mathrm{Ta}_{2} \mathrm{O}_{5}$. These profiles illustrate hybrid composition of the conductive filament in HRRAM. (c) Schematic representation of oxygen and copper ions diffusion under external bias.
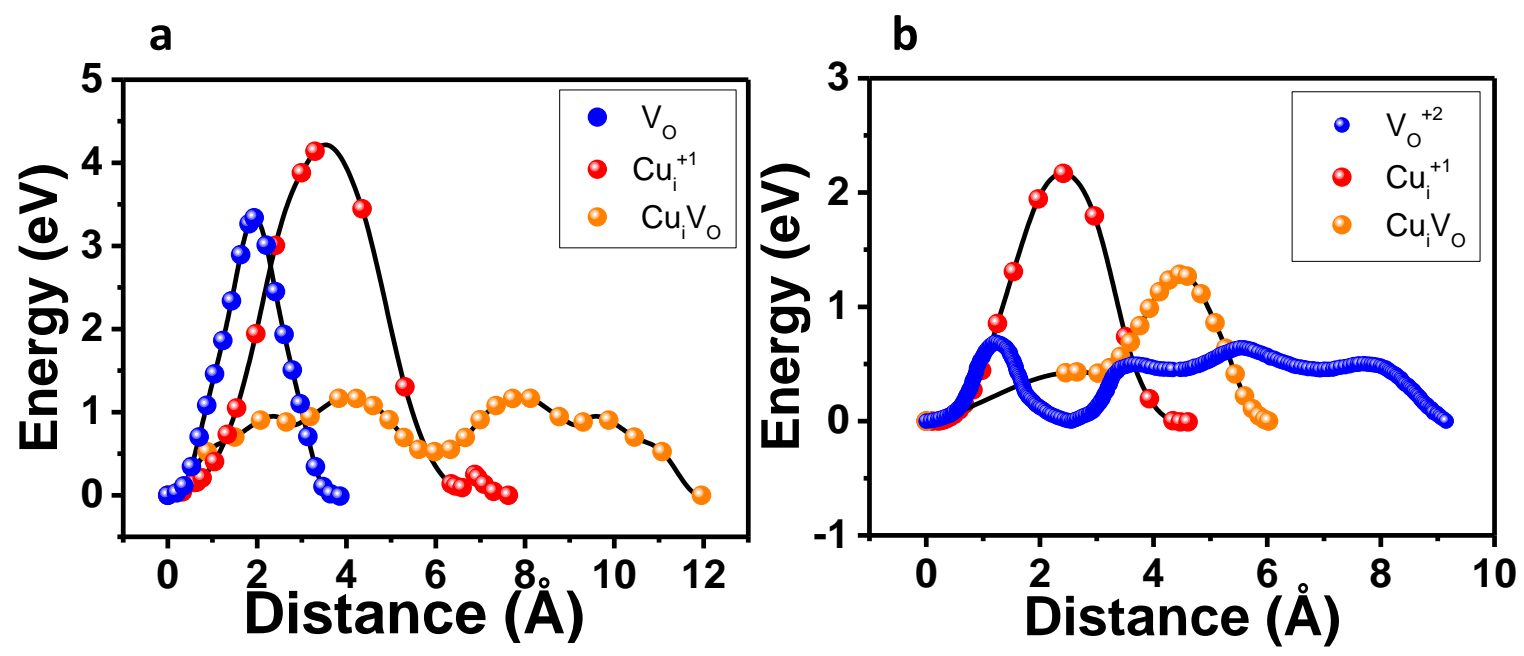

Figure 3. Migration barrier of $\mathrm{V}_{\mathrm{O}}, \mathrm{Cu}_{\mathrm{i}}$ and $\mathrm{Cu}_{\mathrm{i}} \mathrm{V}_{\mathrm{O}}$ between two sites in (a) $\mathrm{Al}_{2} \mathrm{O}_{3} / \mathrm{Cu}$ and (b) $\mathrm{HfO}_{2} / \mathrm{Cu}$ respectively. In $\mathrm{Al}_{2} \mathrm{O}_{3}$, diffusion of $\mathrm{Cu}_{i} \mathrm{~V}_{\mathrm{O}}$ is the most favorable event. On the other hand, in the case of $\mathrm{HfO}_{2}, \mathrm{Cu}_{\mathrm{i}} \mathrm{V}_{\mathrm{O}}$ and $\mathrm{V}_{\mathrm{O}}$ are favorable to diffuse.

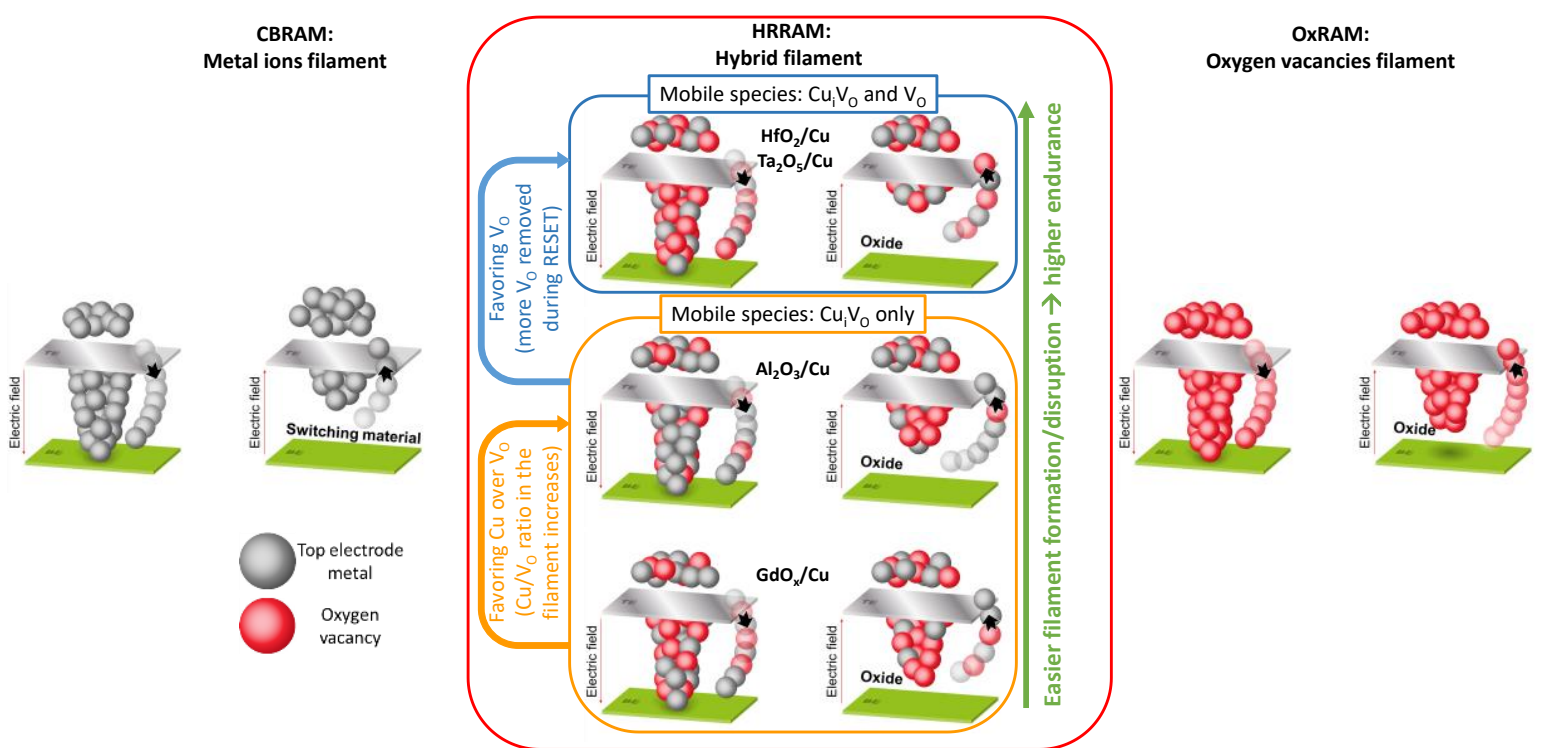

Figure 4. Schematics of filament formation and disruption in different RRAM technologies. CBRAM (left) working principle relies on metal ions, coming from the top electrode, 


\section{WILEY-VCH}

introduction in a switching layer while OxRAM (right) relies on oxygen vacancies formation. Summary of HRRAM filament composition depending on switching materials. Filament is composed of oxygen vacancy $\left(\mathrm{V}_{O}\right)$ and copper introduced next to $\mathrm{V}_{\mathrm{O}}\left(\mathrm{Cu}_{\mathrm{i}} \mathrm{V}_{\mathrm{O}}\right)$. Two HRRAM groups could be distinguished depending on filament composition: 1) $\mathrm{Cu}_{\mathrm{i}} \mathrm{V}_{\mathrm{O}}$ is favored at the expense of $V_{O}$ leading to $V_{O}$ hard to be recovered and low endurance (in orange frame). 2) $V_{O}$ as favorable as $\mathrm{Cu}_{\mathrm{i}} \mathrm{V}_{\mathrm{O}}$ to be removed leads to a $\mathrm{V}_{\mathrm{O}}$ easy to recover and thus high endurance (in blue frame). In the first group, Vo is still necessary to form the filament but it is harder to remove than $\mathrm{Cu}_{\mathrm{i}} \mathrm{V}_{\mathrm{O}}$. Group 1 presents thus earlier oxide degradation leading to a low endurance. However, favoring $\mathrm{Cu}_{\mathrm{i}} \mathrm{V}_{\mathrm{O}}$ by decreasing its formation enthalpy and migration energy barrier improves endurance $\left(\mathrm{Al}_{2} \mathrm{O}_{3} / \mathrm{Cu}\right.$ versus $\left.\mathrm{GdO}_{\mathrm{x}} / \mathrm{Cu}\right)$. To further improve endurance, equilibrium between $\mathrm{V}_{\mathrm{O}}$ and $\mathrm{Cu}_{i} \mathrm{~V}_{\mathrm{O}}$ is necessary (group 2). Formation enthalpy and migration energy barrier for both species become of the same order of magnitude leading to filament formation and disruption at a low energy budget.

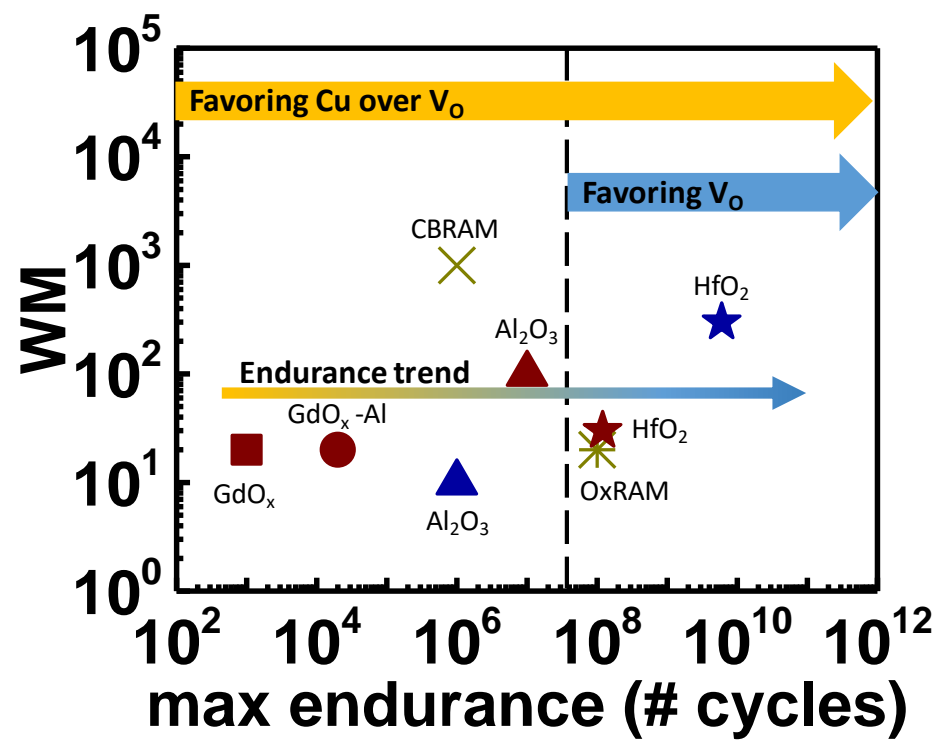

b

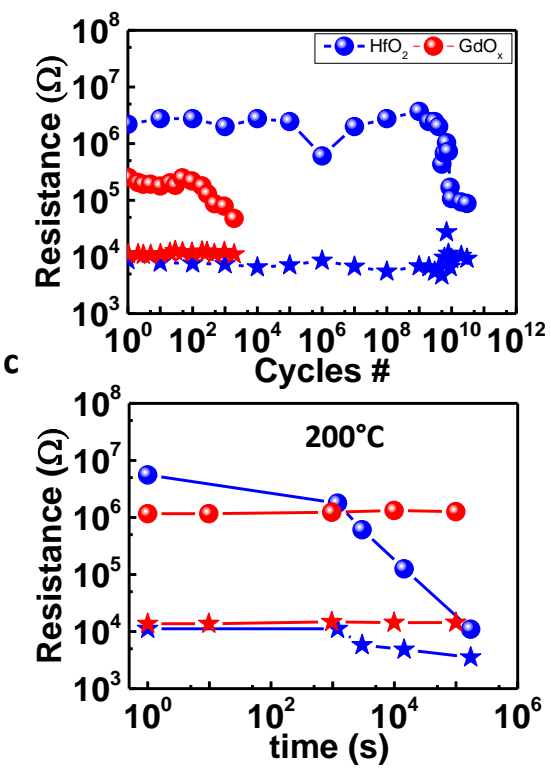

Figure 5. (a) Maximum endurance reached for all studied materials. TiN bottom electrode in red and $\mathrm{W}$ in blue. $\mathrm{Ag} / \mathrm{GeS}_{2} \mathrm{CBRAM}$ and $\mathrm{HfO}_{2} / \mathrm{Ti}$ OxRAM are also presented. The black dashed line separates the two groups of HRRAM depending on their filament composition. On the left side, decreasing $\mathrm{Cu}_{\mathrm{i}} \mathrm{V}_{\mathrm{O}}$ formation enthalpy and diffusion barrier in oxide improves endurance (left arrow). However, on the right side, having $V_{0}$ formation enthalpy and diffusion barrier of the same order of magnitude as $\mathrm{Cu}_{\mathrm{i}} \mathrm{V}_{\mathrm{O}}$ avoid early oxide degradation leading to a better endurance (blue arrow). Endurance trend depending on copper and oxygen vacancies balance in the switching filament composition regardless WM is presented. (b) and (c) comparison between best case and worst case for cycling endurance and data retention respectively. 


\section{WILEY-VCH}

Table 1. Migration energy barrier, $E_{a}$, and formation enthalpy, $\Delta H$, between the top electrode and various oxides extracted from atomistic simulations. Parenthesis represent the charge of the mobile defect.

\begin{tabular}{|c|c|c|c|c|c|c|c|c|c|}
\hline \multirow{2}{*}{$\begin{array}{c}\text { Defect } \\
{[\mathrm{eV}] \mathrm{l}}\end{array}$} & \multicolumn{2}{|c|}{$\mathrm{HfO}_{2}$} & \multicolumn{2}{|c|}{$\mathrm{Ta}_{2} \mathrm{O}_{5}$} & \multicolumn{2}{|c|}{$\mathrm{Al}_{2} \mathrm{O}_{3}$} & \multicolumn{2}{|c|}{$\mathrm{GdO}_{x}$} & \multirow{2}{*}{$\begin{array}{c}\mathrm{GdO}_{\mathrm{x}}-\mathrm{A} \\
\Delta \mathrm{H}\end{array}$} \\
\hline & $\Delta \mathrm{H}$ & $E_{a}$ & $\Delta \mathrm{H}$ & $E_{a}$ & $\Delta \mathrm{H}$ & $E_{a}$ & $\Delta \mathrm{H}$ & $E_{a}$ & \\
\hline $\mathrm{Cu}_{\mathrm{i}}^{1+}$ & 3.4 & 2.5 & 1.3 & $x$ & 2.5 & 4 & 3.2 & 2 & 3.6 \\
\hline $\mathrm{V}_{0}{ }^{\mathrm{x}}$ & $2.5(+2)$ & $0.7(+2)$ & $2.4(+2)$ & $0.38(+2)$ & $3.8(0)$ & $3.5(0)$ & $<3.5(0)$ & $x$ & $<3.5(0)$ \\
\hline$\left(\mathrm{Cu}_{\mathrm{i}} \mathrm{V}_{\mathrm{O}}\right)^{+1}$ & 2.6 & 1.3 & 0.5 & $x$ & 0.6 & 1.4 & 1.3 & 3.44 & -0.2 \\
\hline Filament & \multicolumn{4}{|c|}{$V_{o}$ and $\mathrm{Cu}_{\mathrm{i}}$ next to $\mathrm{V}_{\mathrm{o}}$} & \multicolumn{5}{|c|}{$\mathrm{Cu}_{\mathrm{i}}$ next to $\mathrm{V}_{\mathrm{o}}$} \\
\hline
\end{tabular}




\section{WILEY-VCH}

Copyright WILEY-VCH Verlag GmbH \& Co. KGaA, 69469 Weinheim, Germany, 2016.

\section{Supporting Information}

Title Hybrid-RRAM Towards Next Generation of Non-volatile Memory: Coupling of Oxygen Vacancies and Metal Ions

Author(s), and Corresponding Author(s)* Gilbert Sassine*, Cécile Nail, Philippe Blaise, Benoit Sklenard, Mathieu Bernard, Rémy Gassilloud, Aurélie Marty, Marc Veillerot, Christophe Vallée, Etienne Nowak, and Gabriel Molas*

\section{ToF-SIMS Measurements}

ToF-SIMS measurements were done on $\mathrm{Ta}_{2} \mathrm{O}_{5} / \mathrm{Cu}$ based stack in HRS and LRS. The tested stack was as follows: Ta $(200 \mathrm{~nm}) / \mathrm{TiN}(5 \mathrm{~nm}) / \mathrm{Ta}_{2} \mathrm{O}_{5}(10 \mathrm{~nm}) / \mathrm{Ti}(1 \mathrm{~nm}) / \mathrm{CuTe}_{2} \mathrm{Ge}(15 \mathrm{~nm}) / \mathrm{TiN}$ (5nm) as presented in Figure S1.a. For LRS a ramp voltage was applied with a compliance current fixed at $5 \times 10^{-3} \mathrm{~A}$ (figureS1.b). Then a sputter guns with $500 \mathrm{eV} \mathrm{O}_{2}$ or $\mathrm{Cs}$ were used, with an ion detection mode with $\mathrm{Bi}^{+}$and $\mathrm{Bi}^{3+}$ ions at $25 \mathrm{keV}$ and a detection of positive ions in $\mathrm{M}^{+}, \mathrm{M}^{-}$and $\mathrm{MCs}^{+}$modes. ToF-SiMS spectra presented in Figure 2 in the main text show the diffusion of copper and from $\mathrm{CuTe}_{2} \mathrm{Ge} / \mathrm{Ti}$ toward $\mathrm{Ta}_{2} \mathrm{O}_{5}$ during SET operation. On the other hand, spectra shows diffusion of oxygen from the oxide toward top electrode forming oxygen vacancies in the vicinity of the dielectric.

\section{Electrical Characterization}

To study the technology choice impact on endurance, we compare the best endurance that could be reached for different stacks. First, we compare $\mathrm{HfO}_{2} / \mathrm{Cu}$ based $\mathrm{HRRAM}$ with a typical $\mathrm{HfO}_{2} / \mathrm{Ti}$ OxRAM to identify the impact of $\mathrm{Cu}$ presence in the switching filament on device characteristics. Then we identify different type of filament behavior by changing the switching material in memory stack. Four HRRAM cases are studied $\left(\mathrm{HfO}_{2} / \mathrm{Cu}, \mathrm{Al}_{2} \mathrm{O}_{3} / \mathrm{Cu}\right.$, $\mathrm{GdO}_{\mathrm{x}} / \mathrm{Cu}$ and $\left.\mathrm{GdO}_{\mathrm{x}}-\mathrm{Al} / \mathrm{Cu}\right)$. 


\section{WILEY-VCH}

\subsection{HRRAM versus OxRAM}

In order to identify $\mathrm{Cu}$ contribution in $\mathrm{HRRAM}$, typical $\mathrm{HfO}_{2} / \mathrm{Ti}$ OxRAM is compared with $\mathrm{HfO}_{2} / \mathrm{Cu} \mathrm{HRRAM}$. Figure $\mathbf{S 2}$.a and $\mathbf{c}$ illustrate the maximum endurance that could be achieved for both technologies with two different bottom electrodes. In the case of tungsten BE, HRRAM presents higher maximum endurance as $6.10^{9}$ cycles could be reached before degradation, versus $10^{8}$ in OxRAM. In the case where TiN is used as BE, no clear effect is noticed. However, retention measurements show that OxRAM presents higher stability over time than HRRAM. For both BEs no resistance variation is observed after $24 \mathrm{~h}$ at $200^{\circ} \mathrm{C}$ for $\mathrm{HfO}_{2} / \mathrm{Ti}$, while HRS failure (resistance drift towards lower values) is obtained in the case of HRRAM (figure S2.b and d). BE impact on device performance is not treated in this study. In a previous work ${ }^{[22]}$ a trade-off between WM, endurance and retention can be found in HRRAM. Increasing WM and endurance in the case of $\mathrm{W} / \mathrm{HfO}_{2} / \mathrm{Cu}$ compared to $\mathrm{W} / \mathrm{HfO}_{2} / \mathrm{Ti}$ leads to a degraded retention (W BE is chosen as maximum endurance has been reached). This has been correlated to the energy migration barrier of the species composing the filament. Decreasing this energy leads to a degraded retention. It can be noted that a correlation with a typical CBRAM behavior can be made; $\mathrm{Ag} / \mathrm{GeS}_{2}$ presents high $\mathrm{WM}$, a relatively high endurance and a poor retention due to the metallic filament feature ${ }^{[11]}$. Thus, the low retention stability of $\mathrm{HfO}_{2} / \mathrm{Cu}$ could be due to $\mathrm{Cu}$ metal ions insertion into filament composition. $\mathrm{Cu}$ presence in the filament could be noticed as well by studying SET behavior in both technologies.

\subsection{Copper Impact on Switching Behavior}

In the aim of studying copper metal ions contribution in the oxide, a quasi-static voltage ramp is applied on 1T1R 4kbs memory arrays ${ }^{[18]}$. This method allows the measurement of switching voltage and switching time in a memory device. It consists in continuously increasing the applied voltage at different ramp rate until switching occurs (inset of Figure S3). The voltage stress is applied on $\mathrm{HfO}_{2} / \mathrm{Ti}$ OxRAM and $\mathrm{HfO}_{2} / \mathrm{Cu} \mathrm{HRRAM}$ in both SET 


\section{WILEY-VCH}

(HRS to LRS) and RESET (LRS to HRS) respectively. Figure S3 represents switching time in logarithmic scale versus switching voltage. Based on a previews study ${ }^{[18]}$ it was shown that in Ramped Voltage Stress the switching time effect is not cumulative. Consequently, the switching time is computed from the starting of the voltage step where the switching occurs. It can be noticed that when a positive voltage is applied on the top electrode (TE), a lower voltage is needed to SET HRRAM compared to OxRAM. However, the same behavior is observed in RESET for both HRRAM and OXRAM. In SET (positive voltage on the TE), copper ions insertion in the oxide favors the filament formation. Thus lower energy is required to SET the HRRAM.

\subsection{HRRAM with Stable Retention}

As $\mathrm{Cu}$ ions contribution to the filament formation was identified in HRRAM, different behavior are evaluated by changing switching material. In order to show its impact on endurance, $\mathrm{Al}_{2} \mathrm{O}_{3}$ and $\mathrm{GdO}_{\mathrm{x}}$ known as typical materials for high retention are studied ${ }^{[29.30]}$.

Figure S4.a and $\mathbf{c}$ show the retention stability of $\mathrm{Al}_{2} \mathrm{O}_{3} / \mathrm{Cu}$ with two different BEs (TiN and W) and $\mathrm{TiN} / \mathrm{GdO}_{\mathrm{x}} / \mathrm{Cu}$ respectively. There is no resistance variation measured for both materials at $200^{\circ} \mathrm{C}$. However, as shown in figure $\mathrm{S} 4 \mathrm{~b}$ and $\mathrm{d}$, where the best case of endurance are presented, $\mathrm{Al}_{2} \mathrm{O}_{3}$ and $\mathrm{GdO}_{\mathrm{x}}$ show lower cycling endurance than $\mathrm{HfO}_{2} / \mathrm{Cu}$ regardless of the chosen WM; $10^{7}$ and $10^{6}$ cycles are reached in the case of $\mathrm{TiN} / \mathrm{Al}_{2} \mathrm{O}_{3} / \mathrm{Cu}$ (high WM) and $\mathrm{W} / \mathrm{Al}_{2} \mathrm{O}_{3} / \mathrm{Cu}$ (low $\mathrm{WM}$ ) respectively. In the case of $\mathrm{GdO}_{\mathrm{x}} / \mathrm{Cu}$ the maximum cycling endurance we could attain is at the order of $10^{3}$. Trying to reach $\mathrm{Al}_{2} \mathrm{O}_{3}$ endurance characteristics, $\mathrm{GdO}_{\mathrm{x}}$ has been doped with Aluminum (Al). An improvement in cycling endurance is noticed in $\mathrm{GdO}_{\mathrm{x}}-\mathrm{Al} / \mathrm{Cu}$ compared to $\mathrm{GdO}_{\mathrm{x}} / \mathrm{Cu}$ as shown in figure $\mathrm{S} 4 \mathrm{~d}$. Figure $\mathrm{S} 4 \mathrm{c}$ shows no resistance variation at $200^{\circ} \mathrm{C}$. In conclusion, regardless the chosen $\mathrm{WM}, \mathrm{Al}_{2} \mathrm{O}_{3}$ and $\mathrm{GdO}_{\mathrm{x}}$ cannot reach $\mathrm{HfO}_{2} / \mathrm{Cu}$ performance in terms of endurance.

\subsection{Forming Polarity}




\section{WILEY-VCH}

In this part, forming is studied in $\mathrm{HfO}_{2} / \mathrm{Cu}$ and $\mathrm{Al}_{2} \mathrm{O}_{3} / \mathrm{Cu}$ HRRAM. Two different

polarizations are applied using the quasi-static method presented above: direct forming where the forming voltage is applied on the top electrode and reverse forming where the forming voltage is applied on the bottom electrode. Direct forming implies Copper $(\mathrm{Cu})$ and oxygen vacancies $\left(\mathrm{V}_{\mathrm{O}}\right)$ formation in the vicinity of the oxide while in reverse forming, as $\mathrm{Cu}$ is positively polarized, its introduction in the oxide is thus not possible. In this case, only $\mathrm{V}_{\mathrm{O}}$ formation is considered. In this study, Figure $\mathbf{S 5}$ represents the time to breakdown tBD vs $\mathrm{V}_{\text {switch }}$ for direct and reverse forming. For $\mathrm{HfO}_{2} / \mathrm{Cu}$, $\mathrm{t}_{\mathrm{BD}}$ and $\mathrm{V}_{\text {switch }}$ are similar in direct and reverse forming. In the case of $\mathrm{Al}_{2} \mathrm{O}_{3} / \mathrm{Cu}$, higher reverse forming voltage is observed for short tBD. $\mathrm{HfO}_{2} / \mathrm{Cu}$ shows similar switching mechanism in both polarizations while $\mathrm{Al}_{2} \mathrm{O}_{3} / \mathrm{Cu}$ exposes different working principle depending on polarization. $\mathrm{In} \mathrm{HfO}_{2} / \mathrm{Cu}$, as $\mathrm{V}_{\mathrm{O}}$ are as favorable as $\mathrm{Cu}_{\mathrm{i}} \mathrm{V}_{\mathrm{O}}$, no real impact of copper insertion on oxide breakdown is observed; same behavior is noticed in direct and reverse forming. However, in the case of $\mathrm{Al}_{2} \mathrm{O}_{3}$, where $\mathrm{Cu}_{\mathrm{i}} \mathrm{V}_{\mathrm{O}}$ are more favorable than $\mathrm{V}_{\mathrm{O}}$, the filament formation requires lower voltage in direct forming where $\mathrm{Cu}_{\mathrm{i}} \mathrm{V}_{\mathrm{O}}$ dominates the switching mechanism compared to reverse forming where only Vo controls the switching.

a

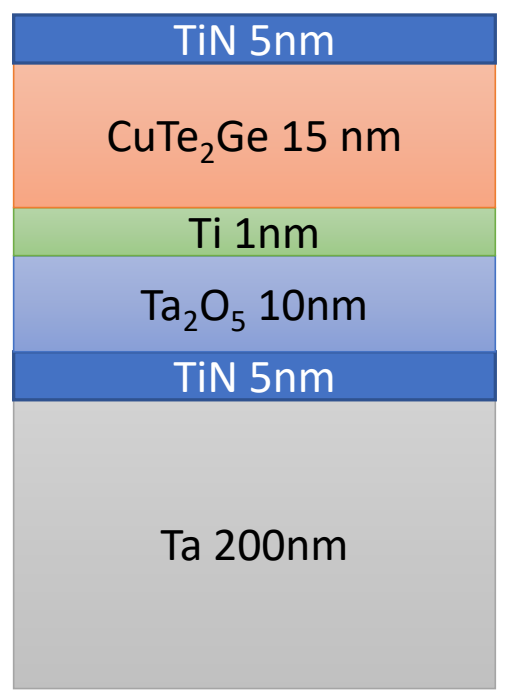

b

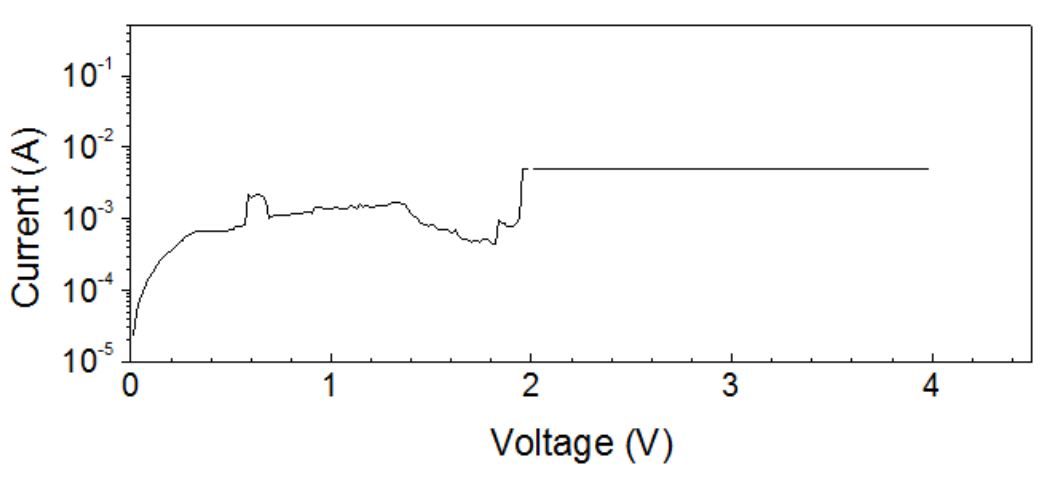

Figure S1. (a) studied stack in ToF-SIMS. (b) Current voltage characteristic of the studied device during SET operation. 

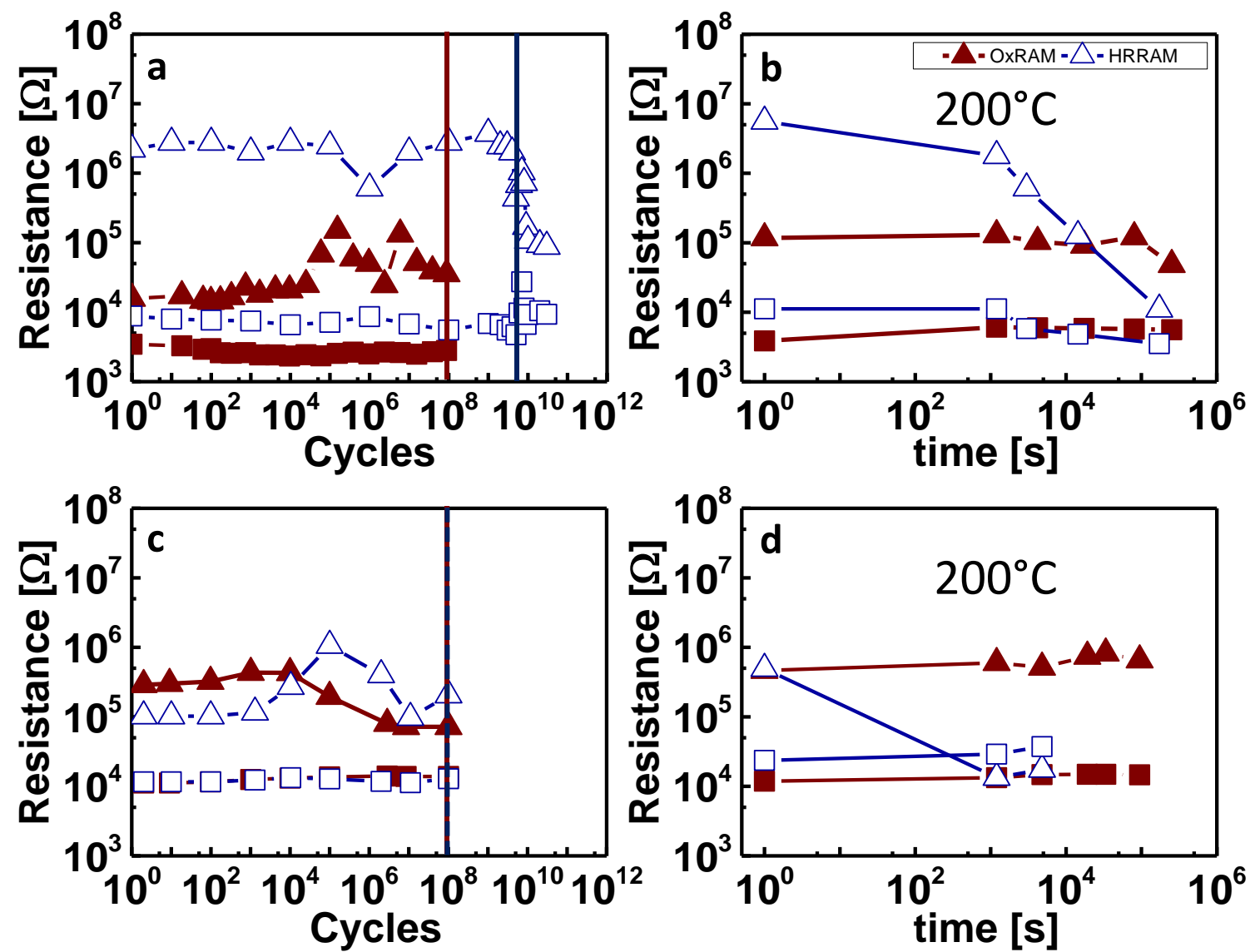

Figure S2. (a) Endurance and retention (at $200^{\circ} \mathrm{C}$ ) measurement for (a), (b) $\mathrm{W} / \mathrm{HfO}_{2} / \mathrm{Cu}$ and $\mathrm{W} / \mathrm{HfO}_{2} / \mathrm{Ti}$ and (c), (d) $\mathrm{TiN} / \mathrm{HfO}_{2} / \mathrm{Cu}$ and TiN/HfO $/ \mathrm{Ti}$. In (a) and (c) lines designates the maximum number of cycles reached before filament degradation. In W/HfO $/ \mathrm{Cu} 610^{9}$ are reached versus $10^{8}$ for $\mathrm{W} / \mathrm{HfO}_{2} / \mathrm{Ti}$ (a). As for TiN bottom electrodes (c), $10^{8}$ could be reached for both OXRAM and HRRAM. 24 hours stability is reached for OxRAM (W and TiN BE) while HRS failure is clearly observed in HRRAM (b) and (d).

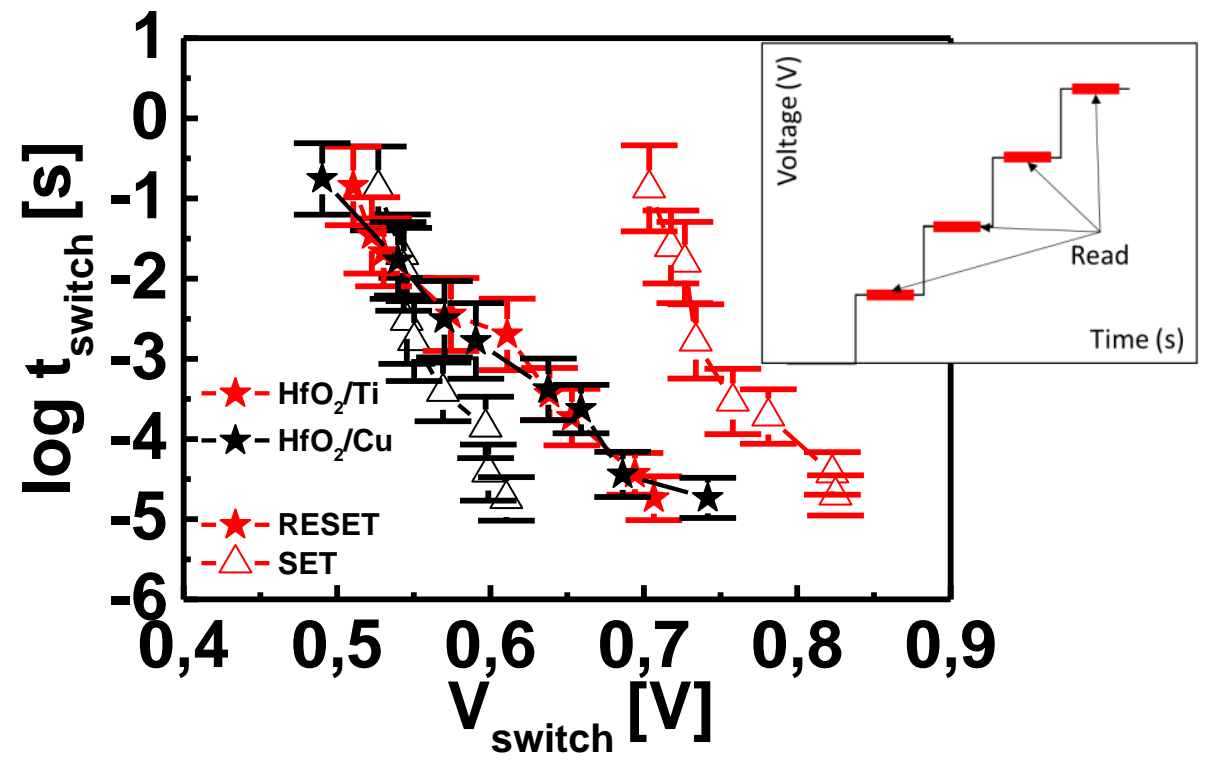

Figure S3. (a) $t_{\text {switch }}$ versus $\mathrm{V}_{\text {switch }}$ in SET and RESET for $\mathrm{HfO}_{2} / \mathrm{Cu}$ and $\mathrm{HfO}_{2} / \mathrm{Ti}$. 
WILEY-VCH
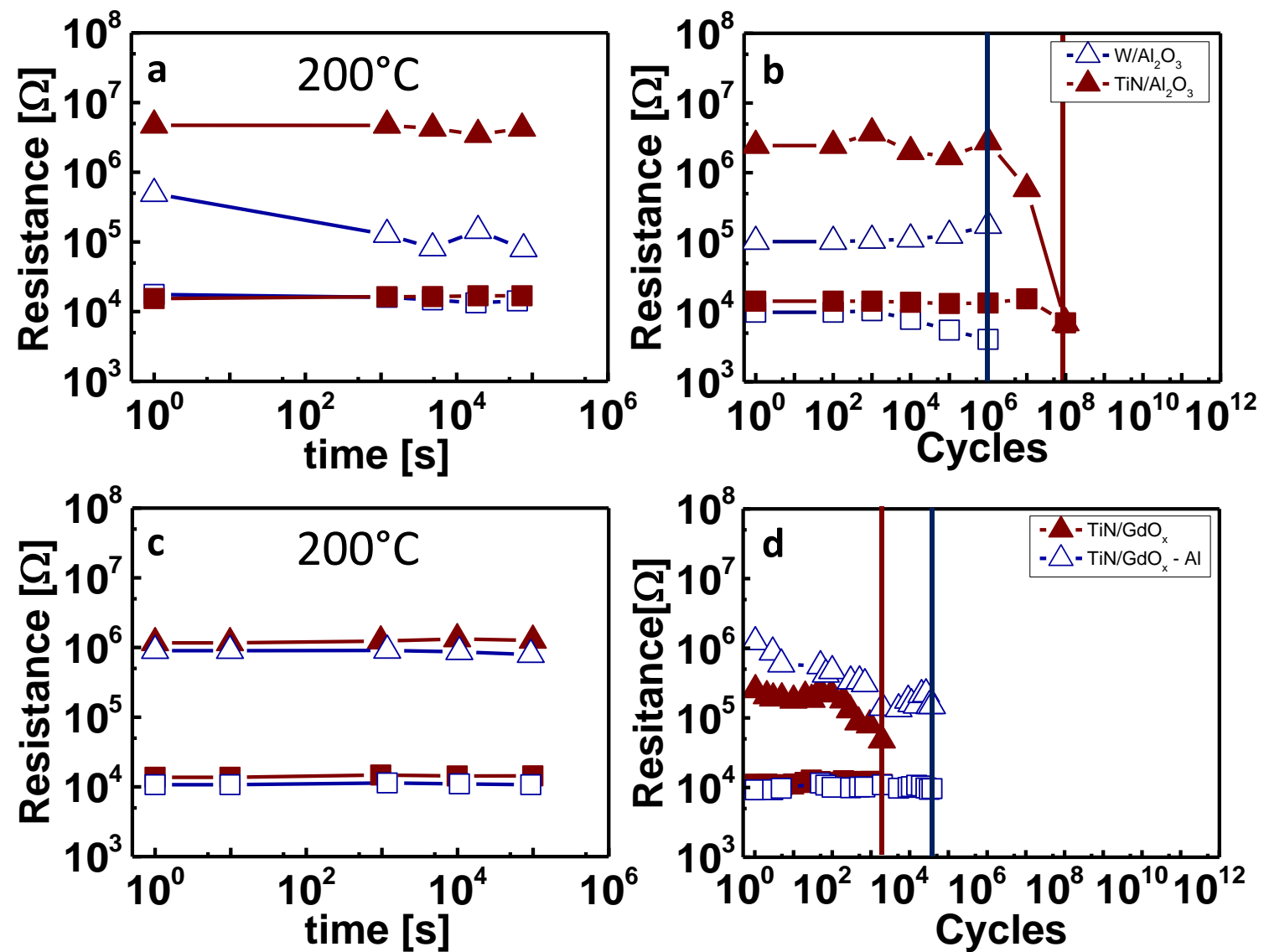

Figure S4. Retention at $200^{\circ} \mathrm{C}$ and endurance measurement for (a), (b) $\mathrm{W} / \mathrm{Al}_{2} \mathrm{O}_{3} / \mathrm{Cu}$ and $\mathrm{TiN} / \mathrm{Al}_{2} \mathrm{O}_{3} / \mathrm{Cu}$. and (c), (d) $\mathrm{TiN} / \mathrm{GdO}_{\mathrm{x}} / \mathrm{Cu}$ and $\mathrm{TiN} / \mathrm{GdO}_{\mathrm{x}}-\mathrm{Al} / \mathrm{Cu}$. 24 hours stability is reached for all tested HRRAM devices (a) and (c). Lines designates the maximum number of cycles reached before filament degradation. In $\mathrm{W} / \mathrm{Al}_{2} \mathrm{O}_{3} / \mathrm{Cu} 10^{6}$ cycles are reached versus $10^{7}$ cycles for $\mathrm{TiN} / \mathrm{Al}_{2} \mathrm{O}_{3} / \mathrm{Cu}$ (b). As for $\mathrm{GdO}_{\mathrm{x}}(\mathrm{d}), 10^{3}$ cycles are reached, whereas up to $510^{4}$ cycles are obtained after $\mathrm{Al}$ doping.

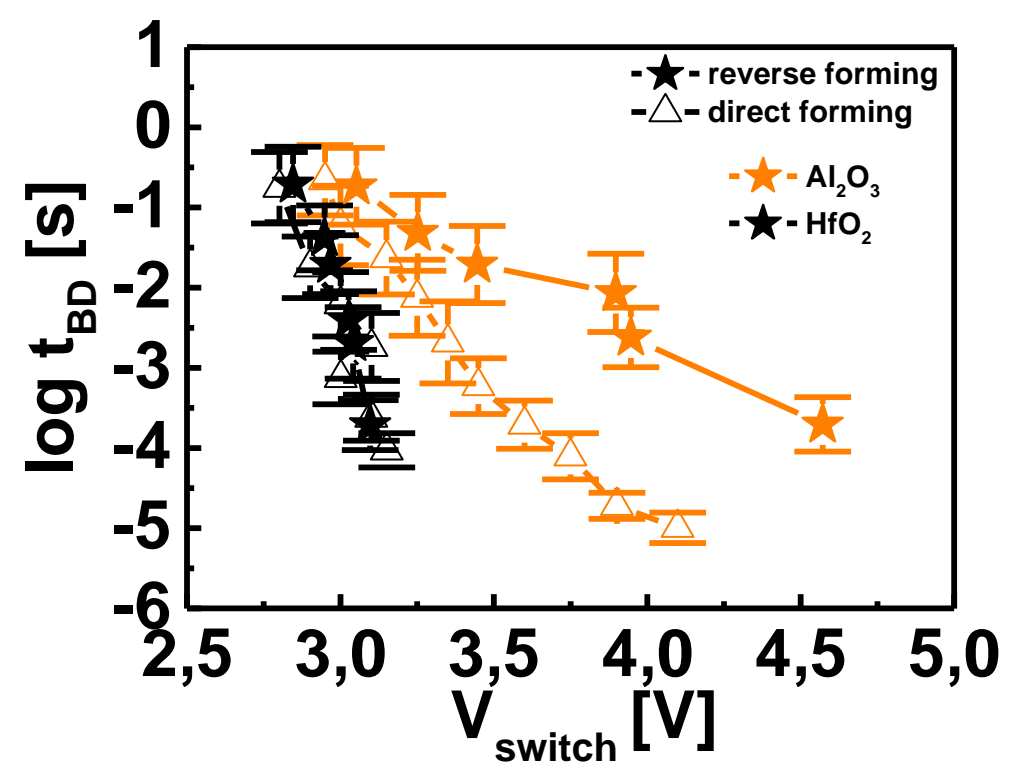

Figure S5. (a) tBD versus forming voltage in direct and reverse polarity for $\mathrm{HfO}_{2} / \mathrm{Cu}$ and $\mathrm{Al}_{2} \mathrm{O}_{3} / \mathrm{Cu}$. 